\title{
Conservação de rúcula minimamente processada produzida em campo aberto e cultivo protegido com agrotêxtil
}

\author{
Angela F Gonzalez; Ricardo Antonio Ayub; Marie Y Reghin \\ UEPG-Dep ${ }^{\text {to }}$ Fitotecnia e Fitossanidade; Av. Carlos Cavalcanti 4748, 84030-900 Ponta Grossa-PR; E-mail: angela.fuentes@uol.com.br; \\ rayub@uepg.br; feghin@convoy.com.br
}

\section{RESUMO}

Folhas de rúcula produzidas em campo aberto e sob cultivo protegido com agrotêxtil foram minimamente processadas, embaladas inteiras ou picadas em bandejas de poliestireno expandido e cobertas com filme de PVC de 14 micras. O delineamento adotado foi o inteiramente casualizado em esquema fatorial $2 \times 2 \times 2$ (ambiente de cultivo, forma de preparo e refrigeração a $0^{\circ} \mathrm{C}$ e $10^{\circ} \mathrm{C}$ ), com quatro repetições por tratamento, totalizando 32 bandejas. Os tratamentos foram armazenados a $0^{\circ} \mathrm{C}$ e $10^{\circ} \mathrm{C}$ por 10 dias, quando foram avaliadas as variáveis perda de massa $(\%)$; $\mathrm{pH}$; sólidos solúveis; acidez titulável; cor e aparência. A conservação a $0^{\circ} \mathrm{C}$ promoveu uma diminuição da perda de peso da rúcula minimamente processada. A utilização de folhas inteiras ou minimamente processadas foi significativa para sólidos solúveis sendo os maiores valores encontrados para as folhas inteiras. Para folhas picadas observou-se valores de acidez significativamente maiores para as produzidas sob ambiente natural. Independente da forma de preparo, a rúcula produzida em ambiente natural apresentou menor valor de $\mathrm{pH}$. A cor e aparência da rúcula não foram influenciadas pelos tratamentos.

Palavras-chave: Eruca sativa L., polipropileno, vida de prateleira.

\begin{abstract}
Conservation of minimally processed rocket produced under open field conditions and non woven polypropylene

Leaves of rocket salad produced under open field and non woven polypropylene were minimally processed and packed entire or pricked in polyestyrene trays covered with PVC film of 14 micras. The treatments were stored at $0^{\circ} \mathrm{C}$ and $10^{\circ} \mathrm{C}$ per 10 days, when the variables weight loss (\%); pH; soluble solids; titratable acidity; colour and appearance were evaluated. The conservation under $0^{\circ} \mathrm{C}$ promoted a reduction of weight loss on rocket salad minimally processed. Using entire or minimally processed leaves were significant for soluble solids the biggest values being found for entire leaves. For pricked leaves bigger values of acidity were observed for the produced ones under natural environment. Independent of the preparation form rocket salad produced under natural environment presented minor value of $\mathrm{pH}$. The color and appearance of rocket salad were not influenced by the treatments.
\end{abstract}

Keywords: Eruca sativa; nonwoven of polypropylene; shelf life.

(Recebido para publicação em 2 de dezembro de 2005; aceito em 31 de agosto de 2006)

$\mathrm{P}$ rodutos minimamente processados são aqueles submetidos a operações de limpeza, lavagem, seleção, descascamento, corte, embalagem e armazenamento, mas que apresentam qualidade semelhante ao produto fresco (Chitarra, 2000).

Na produção de hortaliças minimamente processadas, normalmente empregam-se as cultivares que melhor se adaptam ao processamento, sendo esta preferência atribuída a fatores relacionados a características de matéria prima que favoreçam o frescor do produto final e fatores econômicos (Ferrari et al., 2001). A qualidade dos vegetais minimamente processados é dada pela combinação de atributos que determinam seu valor alimentício. Uma maior ênfase é dada para a aparência e a forma. O produto deve ser consistente, ter aparência fresca, ser de cor aceitável, razoavelmente livre de defeitos e livre de inócuos (Shewfelt et al., 1987).
A rúcula é uma hortaliça folhosa originária da região Mediterrânea, muito popular nas regiões de colonização italiana no Brasil. Rica em potássio, enxofre, ferro e vitaminas A e C, é apreciada pelo sabor picante e cheiro agradável e acentuado (Trani \& Passos, 1998). O aumento do consumo desta hortaliça tem sido observado em sua forma minimamente processada, ou seja, com as folhas já lavadas, higienizadas e prontas para o consumo (Sigrist, 2002). Segundo Cantwell (2001), a rúcula deve ser armazenada a $0^{\circ} \mathrm{C}$, umidade relativa $95-100 \%$ por 7 a 10 dias, tendo uma baixa produção de etileno $(<0,1 \mathrm{~mL}$. $\left.\mathrm{Kg}^{-1} \cdot \mathrm{h}^{-1}\right)$. Quando conservada a $20^{\circ} \mathrm{C}$, é alta sua susceptibilidade ao dano provocado pela presença de etileno.

O cultivo da planta pode ser realizado em ambiente natural e sob cultivo protegido. $\mathrm{O}$ cultivo protegido pode ser feito com o polipropileno, conhecido como agrotêxtil, que é usado como uma manta flutuante sobre as plantas com boas respostas para o cultivo de folhosas (Reghin et al., 2001; 2002). Entretanto, pouco ainda se conhece sobre o efeito do cultivo protegido no comportamento pós-colheita destes produtos.

O objetivo do presente trabalho foi avaliar o comportamento pós-colheita de rúcula minimamente processada, produzidas em ambiente natural e sob cultivo protegido com agrotêxtil, embaladas em bandejas de isopor recobertas com PVC e armazenadas a $0^{\circ} \mathrm{C}$ e a $10^{\circ} \mathrm{C}$, por 10 dias.

\section{MATERIAL E MÉTODOS}

O experimento foi conduzido na Universidade Estadual de Ponta Grossa (PR), sendo a rúcula coletada na área de olericultura da Fazenda-Escola, pertencente à Universidade, produzidas sob cultivo protegido, com as plantas cobertas com agrotêxtil como uma manta flu- 
tuante e em ambiente natural. A colheita foi realizada procedendo o corte das plantas rente ao sistema radicular. As plantas dos dois ambientes de cultivos foram levadas para o laboratório para os procedimentos de pós-colheita. Primeiramente, foram pré-refrigeradas, com seus pecíolos imersos em água e armazenada durante 12 horas a $10 \pm 2^{\circ} \mathrm{C}$ até seu processamento. Decorrido este período, as folhas foram selecionadas e padronizadas pelo tamanho, aparência e integridade e lavadas em água corrente. A metade do material foi separado e folhas inteiras foram sanitizadas com solução contendo $150 \mathrm{mg} . \mathrm{L}^{-1}$ de cloro ativo a $5^{\circ} \mathrm{C}$ durante 10 minutos. $\mathrm{O}$ enxágüe foi feito com solução a $3 \mathrm{mg} . \mathrm{L}^{-1}$ de cloro ativo a $5^{\circ} \mathrm{C}$ por 10 minutos. As folhas foram centrifugadas por $5 \mathrm{minu}$ tos em centrífuga manual e embaladas em bandejas de isopor recobertas com PVC de 14 micras. A outra metade foi picada na espessura de 1-3 mm com facas de aço inoxidável e enxaguadas para retirada do suco celular proveniente do corte. O produto foi então sanitizado, centrifugado e embalado da mesma forma das folhas inteiras. Os tratamentos foram armazenados a $0^{\circ} \mathrm{C}$ no freezer e a $10^{\circ} \mathrm{C}$ no refrigerador por 10 dias. Os seguintes parâmetros físico-químicos foram avaliados: perda de massa (\%), determinado pela diferença de massa pesada em balança digital entre a data inicial e final; $\mathrm{pH}$, determinado através de leitura direta em potenciômetro do material processado em água destilada em processadora de uso doméstico. Os sólidos solúveis foram determinados pela leitura direta do material processado em refratômetro manual com correção a $20^{\circ} \mathrm{C}$. A acidez titulável foi determinada titulando-se a amostra até pH 8.1, com resultado expresso em g.ml ${ }^{-1}$ de ácido málico (Carvalho et al., 1990) e a cor e aparência do produto foram avaliados visualmente aos 10 dias. $\mathrm{O}$ delineamento adotado foi o inteiramente casualizado em esquema fatorial $2 \times 2 \times 2$ (ambiente de cultivo, forma de preparo e refrigeração a $0^{\circ} \mathrm{C}$ e $10^{\circ} \mathrm{C}$ ), com quatro repetições por tratamento, totalizando 32 bandejas. Os resultados foram submetidos à análise de variância e as médias comparadas pelo teste de Tukey no nível de 5\% de probabilidade.

Tabela 1. Perda de massa e $\mathrm{pH}$ de rúcula minimamente processada, produzida sob agrotêxtil e em ambiente natural, inteira e picada, conservada a $0^{\circ} \mathrm{C}$ e $10^{\circ} \mathrm{C}$. Ponta Grossa, UEPG, 2003.

\begin{tabular}{|c|c|c|c|c|}
\hline \multirow{2}{*}{ Tratamentos } & \multicolumn{2}{|c|}{$\begin{array}{c}\text { Perda de massa (\%) (modo } \\
\text { de preparo) }\end{array}$} & \multicolumn{2}{|c|}{ PH (modo de preparo) } \\
\hline & Picado & Inteiro & Picado & Inteiro \\
\hline $10^{\circ} \mathrm{C} /$ Agrotêxtil & $4.66 \mathrm{~A}^{*} \mathrm{a}$ & $4.47 \mathrm{~A} \mathrm{a}$ & $6.70 \mathrm{~A}^{*} \mathrm{a}$ & $5.93 \mathrm{Ab}$ \\
\hline $10^{\circ} \mathrm{C} / \mathrm{Ambiente}$ natural & $4.45 \mathrm{~A} \mathrm{a}$ & $4.80 \mathrm{~A} \mathrm{a}$ & $6.50 \mathrm{Ab}$ & $6.06 \mathrm{~B} \mathrm{~b}$ \\
\hline $0^{\circ} \mathrm{C} /$ Agrotêxtil & $3.29 \mathrm{~A} \mathrm{~b}$ & $2.98 \mathrm{AC}$ & $6.68 \mathrm{~A} \mathrm{a}$ & $6.03 \mathrm{~B} \mathrm{~b}$ \\
\hline $0^{\circ} \mathrm{C} / \mathrm{Ambiente}$ natural & $3.27 \mathrm{~B} \mathrm{~b}$ & $4.04 \mathrm{Ab}$ & $6.40 \mathrm{Ab}$ & $6.24 \mathrm{~B} \mathrm{a}$ \\
\hline
\end{tabular}

*Médias seguidas da mesma letra minúscula na coluna e maiúscula na linha não diferem entre si ao nível de 5\% de probabilidade, pelo teste de Tukey.

Tabela 2. Sólidos solúveis ( ${ }^{\circ}$ Brix) e acidez titulável (ácido málico) de rúcula minimamente processada, produzida sob agrotêxtil e em ambiente natural, inteira e picada, conservada a 0 ${ }^{\circ} \mathrm{C}$ e $10^{\circ} \mathrm{C}$. Ponta Grossa, UEPG, 2003.

\begin{tabular}{|c|c|c|c|c|}
\hline \multirow[t]{2}{*}{ Tratamentos } & \multicolumn{2}{|c|}{$\begin{array}{l}\text { Sólidos Solúveis }\left({ }^{\circ} \text { Brix) }\right. \\
\text { (modo de preparo) }\end{array}$} & \multicolumn{2}{|c|}{$\begin{array}{l}\text { Acidez titulável (\%) } \\
\text { (modo de preparo) }\end{array}$} \\
\hline & Picado & Inteiro & Picado & Inteiro \\
\hline $10^{\circ} \mathrm{C} /$ Ag rotêxtil & $3.27 \mathrm{~B}^{*} \mathrm{~b}$ & $4.25 \mathrm{~A} \mathrm{~b}$ & $0.030 \mathrm{~B}^{*} \mathrm{~b}$ & $0.044 \mathrm{Ab}$ \\
\hline $10^{\circ} \mathrm{C} /$ Ambiente natural & $3.25 \mathrm{~B} \mathrm{~b}$ & $6.00 \mathrm{~A} \mathrm{a}$ & $0.037 \mathrm{~B} \mathrm{a}$ & $0.060 \mathrm{~A} \mathrm{a}$ \\
\hline $0^{\circ} \mathrm{C} /$ Agrotêxtil & $3.37 \mathrm{Ab}$ & $3.62 \mathrm{Ac}$ & $0.030 \mathrm{~B} \mathrm{~b}$ & $0.050 \mathrm{~A} \mathrm{a}$ \\
\hline $0^{\circ} \mathrm{C} / \mathrm{Ambiente}$ natural & $5.00 \mathrm{~B} \mathrm{a}$ & $5.75 \mathrm{~A} \mathrm{a}$ & $0.037 \mathrm{~A} \mathrm{a}$ & $0.030 \mathrm{Ac}$ \\
\hline
\end{tabular}

*Médias seguidas da mesma letra minúscula na coluna e maiúscula na linha não diferem entre si ao nível de 5\% de probabilidade, pelo teste de Tukey.

\section{RESULTADOS E DISCUSSÃO}

Folhas de rúcula armazenadas a $0^{\circ} \mathrm{C}$, apresentaram menor perda de massa, tanto em folhas picadas como nas inteiras, quando comparadas às conservadas a $10^{\circ} \mathrm{C}$ (Tabela 1$)$. A temperatura tem efeito significativo na perda de qualidade, apresentando importante influência no metabolismo do vegetal (Behrsing, 1998). O autor também observou que a vida útil de alface aumentou entre $48 \%$ e $154 \%$ quando a temperatura de armazenamento foi reduzida de $10^{\circ} \mathrm{C}$ para $4,5^{\circ} \mathrm{C}$. Em cenoura picada foi observado que a perda de peso está correlacionada com a perda de qualidade do produto e é dependente da forma de preparo (Tatsumi et al., 1991). Entretanto, a utilização de rúculas inteiras foi significativa para as produzidas em ambiente natural e armazenadas a $0^{\circ} \mathrm{C}$, comparadas com as produzidas sob agrotêxtil. Não foi observada diferença significativa quando as folhas foram picadas.

O produto proveniente de ambiente natural quando picadas, apresentou menores valores de $\mathrm{pH}$ quando compara- das as produzidas sob agrotêxtil (Tabela 1). O modo de preparo foi estatisticamente significativo para $\mathrm{pH}$ em quase todos os tratamentos, sendo observados os maiores valores para as folhas picadas. Sigrist (2002), observou que aumentos de $\mathrm{pH}$ tem sido verificados para diversos produtos inteiros ou que foram minimamente processados e Barry-Ryan \& O'Beirne (1998), atribuem o aumento deste fator ao aumento da carga microbiana observada em produtos minimamente processados, o que está de acordo com Bittencourt et al., (2000), que observaram elevação do $\mathrm{pH}$ de couves armazenadas a $5^{\circ} \mathrm{C}$ por 5 dias.

A forma de preparo foi significativa para sólidos solúveis totais, sendo os menores valores encontrados para as folhas picadas (Tabela 2), o que está de acordo com os resultados encontrados por Roura et al., (2000), em acelgas minimamente processadas, atribuindose este decréscimo ao aumento da atividade respiratória.

Para folhas picadas, conservadas tanto a $0^{\circ} \mathrm{C}$ como a $10^{\circ} \mathrm{C}$, observou-se valores de acidez total titulável significativamente maiores para as produzidas em ambiente natural, quando compara- 
das 'as produzidas sob agrotêxtil (Tabela 2). O aumento da respiração em função da área danificada pelo corte, com conseqüente consumo de ácido orgânico e decréscimo na acidez total titulável podem ser as causas de menores valores para as diferenças entre folhas picadas e inteiras, já que as últimas sofreram apenas os danos mecânicos de separação das folhas (Sigrist, 2002). Observou-se também que a microbiota de folhas de rúcula minimamente processadas aumentou a partir do $3^{\circ}$ dia a $5^{\circ} \mathrm{C}$, podendo dessa forma ser responsável pelo aumento do $\mathrm{pH}$ e diminuição da acidez total titulável (Sigrist, 2002).

A cor e aparência do produto minimamente processado não foram influenciadas pelos tratamentos (dados não demonstrados), sugerindo a possibilidade de extensão do tempo de armazenamento.

Dessa forma, os resultados observados permitiram concluir que a conservação a $0^{\circ} \mathrm{C}$ promove uma diminuição da perda de peso da rúcula minimamente processada. A forma de preparo em folhas inteiras aumenta o teor de sólidos solúveis totais. Os valores de acidez total titulável são maiores para as folhas picadas produzidas em ambiente natural. Os menores valores de $\mathrm{pH}$ foram encontrados em rúcula oriunda de am- biente natural, independente da forma de preparo. A cor e aparência da rúcula minimamente processada não são influenciadas pelos tratamentos.

\section{REFERÊNCIAS}

BARRY-RYAN C; O'BEIRNE D. 1998. Quality and shelf life of fresh cut carrot slices as affected by slicing method. Journal of Food Science 63: 851-856.

BEHRSING JP. 1998. Effect of temperature and size reduction on respiratory activity and shelf life of vegetable. Acta Horticulturae 464: 500506.

BITTENCOURT MT; VANETTI MCD; PUSCHMANN R; PASSOS FJV. 2000. Atividade microbiana em couve minimamente processada. In: ENCONTRO NACIONAL SOBRE PROCESSAMENTO DE FRUTAS E HORTALIÇAS, 2. Resumos... Viçosa: UFV. p. 42.

CANTWELL M. 2001. Características y condiciones recomendadas para el almacenamiento por largo tiempo de frutas y hortalizas frescas. Disponível em http:// postharvest.ucdavis.edu/Produce/Storage/ spanishpropertieschart.pdf. Acessado em 15 maio 2003.

CARVALHO CRL; CARVALHO PRN; MANTOVANI DMB; MORAES RM. 1990. Análises químicas de alimentos. Campinas: ITAL. 121p.

CHITARRA MIF. 2000. Processamento mínimo de frutos e hortaliças. Lavras: UFLA/FAEPE. $113 p$.

FERRARI RA; DEMIATE IM; BARANA AC; HASHIMOTO EM. 2001. Processamento mínimo de hortaliças. Ponta Grossa. (Mimeo).
REGHIN MY; OTTO RF; DALLA PRIA M; FELTRIN AL; VINNE J. 2001. Cobertura do solo e proteção das plantas de pak choi cultivadas com "não tecido" de polipropileno no período de primavera. Horticultura Brasileira 19: 266.

REGHIN MY; OTTO RF; VINNE J; FELTRIN AL. 2002. Produção de repolho branco chinês (pak choi) sob proteção com "não tecido" de polipropileno. Horticultura Brasileira 20: 233236.

ROURA SL; DAVIDOVICH LA; DEL VALLE CE. 2000. Quality loss in minimally processed swiss chard related to amount of damage area. Lebenm-Wiss und Technology 33: 53-59.

SHEWFELT RL, HEATON EK, BATAL KM. 1987. Non destructive color measurement of fresh broccoli. Journal of Food Science 49: 1612.

SIGRIST JMM. 2002. Estudos fisiológicos e tecnológicos de couve flor e rúcula minimamente processadas. Piracicaba: USP. 112p (Tese doutorado).

TATSUMI Y; WATANABE AE; WERIN WP. 1991. Scanning electron microscopy of carrot stick surface to determine cause of white translucent appearance. Journal of Food Science 56: 1357-1359.

TRANI PE; PASSOS FA. 1998. Rúcula (pinchão). In: FAHL JL; CAMARGO MBP; PIZINATTO MA; BETTI JA; MELO AMT; DEMARIA IC; FURLANI AMC (eds). Instruções agrícolas para as principais culturas econômicas. Campinas: IAC. p. 241-242. (IAC. Boletim, 200). 